\title{
MAKING-OF: PROJETOS DE VIDA, PROFISSÕES E CARREIRAS NO PARADIGMA LIFE DESIGN
}

Célio Júnio do Carmo Costa

Universidade Federal de Minas Gerais

\section{Sérgio Dias Cirino}

Universidade Federal de Minas Gerais

Ribeiro, M. A., Teixeira, M. A. P., \& Duarte, M. E. (Eds.). (2019). Life Design: Um paradigma contemporâneo em orientação profissional e de carreira. São Paulo, SP: Vetor.
Recebido em: 14/04/2020

Aceito em: 29/04/2020

\section{RESENHA}

O Aconselhamento Life Design como processo criativo da vida ou Making-of do percurso profissional constitui uma síntese coerente de uma das metáforas descritas no livro Life Design: um paradigma contemporâneo em orientação profissional e de carreira, que descreve a vida profissional como a sequência de vários projetos de trabalho, interconectados por identidade e sentido, que juntos compõem a trajetória profissional do indivíduo. Na obra, os autores abordam as histórias de alguns indivíduos que contaram com o auxílio de profissionais qualificados no uso dessa nova metodologia, que foram convidados a refletir acerca de como o trabalho se integra em suas vidas.

Organizado por Marcelo Afonso Ribeiro, Marco Antônio Pereira Teixeira e Maria Eduarda Duarte, o livro resulta da cooperação entre pesquisadores do Brasil e de Portugal, reunidos no Grupo de Trabalho (Carreiras: informação, orientação e aconselhamento) da Associação Nacional de Pesquisa e Pós-Graduação em Psicologia (ANPEPP). A obra destina-se a profissionais e estudantes das áreas de Psicologia, Pedagogia e Administração, apresentando um conteúdo fundamental que amplia a possibilidade de se discutir o novo paradigma nos países de língua portuguesa. 
O livro esclarece que o paradigma Life Design se originou de várias reuniões de pesquisadores da Europa e dos Estados Unidos, inicialmente na Universidade Livre de Bruxelas (Bélgica), entre 2006 e 2009, com a finalidade de pensar respostas diferentes das apresentadas para a solução de problemas do século 20, e alinhadas ao panorama do século 21. Diante do atual cenário de crises políticas, econômicas e sociais, além de questões ambientais, falta de empregos estáveis e instabilidades diversas, o paradigma propõe responder como "[...] as pessoas podem construir as suas vidas na sociedade em que vivem"? (Ribeiro, Teixeira, \& Duarte, 2019, p. 34).

A obra descreve o Aconselhamento Life Design como uma abordagem que exige dos profissionais treinamentos em análise qualitativa e dialógica. O embasamento das intervenções é de natureza construcionista e construtivista modelos teóricos da Psicologia -, sendo a proposta de trabalho pautada na identificação do(s) tema(s) de vida da pessoa e na construção, reconstrução e coconstrução de pequenas narrativas autobiográficas - relatos pessoais do cliente. Os autores consideram que a produção de sentido, a reflexão e a relação constituem os pilares do Life Design. Assim, estabelecer uma relação orientandoorientador positiva e genuína que favoreça a reflexão e a coordenação dos diálogos é uma condição essencial ao sucesso do aconselhamento.

O livro faz uma apresentação do paradigma, alinhada a resultados de pesquisas, tendo como objetivo favorecer o pensamento, a reflexão crítica e as possibilidades de intervenção relacionadas à proposta. Evidencia, também, como o paradigma Life Design é capaz de estimular uma diversidade de argumentos teóricos e práticas interventivas relacionadas aos princípios de liberdade, justiça e promoção de bem-estar, priorizados pela Declaração Universal dos Direitos Humanos.

A obra está estruturada a partir de uma introdução, seguida de oito capítulos e conclusão. Nos dois primeiros capítulos (Parte I), os autores apresentam os pressupostos teóricos e metodológicos concernentes ao Life Design. Os capítulos seguintes (Parte II) focalizam-se nas intervenções, enquanto as páginas finais apresentam informações referentes aos autores. Com projeto gráfico e capa interessantes e ilustrações e cores coerentes com a proposta, o livro é impresso em papel tom de areia bem suave, o que, aliado à excelente qualidade de impressão, contribui para tornar a leitura mais prazerosa.

Em relação à composição geral da obra, um ponto chama a atenção. Mesmo tendo sido descritos, na primeira parte, os pressupostos teóricos e epistemológicos, os autores, em cada capítulo, introduzem os assuntos a serem abordados, articulam a temática proposta no texto com o paradigma Life Design e apresentam uma conclusão. Longe de soar cansativo, essa estrutura facilita a compreensão das ideias apresentadas e confere ao livro uma qualidade especial, que é a de possibilitar a leitura independente de alguns capítulos, o que pode 
facilitar seu uso como recurso didático em disciplinas de cursos de graduação e pós-graduação.

$\mathrm{Na}$ introdução, os organizadores referem-se ao trabalho como um direito assegurado pela Declaração Universal dos Direitos Humanos, e ressaltam como a realidade do século 21 tem sido falha em garanti-lo a uma parcela considerável da população. O primeiro capítulo, escrito por Maria Eduarda Duarte, uma das idealizadoras do Life Design, evoca o processo histórico do campo de Aconselhamento de Carreira e do Life Design. A autora defende a tese de que o novo paradigma não abre mão do conhecimento científico anterior, mas vai além, ao buscar considerar as possibilidades de construção da vida das pessoas em seus contextos socioculturais específicos.

Ao longo das 177 páginas, os autores demonstram o caráter versátil das intervenções Life Design (LD) e ilustram a aplicabilidade do paradigma em diversos contextos: a) no trabalho com adolescentes; b) com universitários; c) no aconselhamento para o desenvolvimento de carreira de populações desfavorecidas; d) e nas peculiaridades do trabalho formal e informal. Eles defendem o argumento de que há possibilidades de adaptar a proposta LD às intervenções e aos instrumentos que já se mostram eficazes na área da Orientação Profissional e de Carreira.

Em seu artigo, Hartung (2011) sustenta que o Paradigma Life Design, na essência, visa também compreender os benefícios das emoções para a construção das narrativas autobiográficas e a reflexividade dos clientes. O autor considera a necessidade de pesquisas que busquem esclarecer como as emoções podem auxiliar em relação à tomada de decisões e à construção das carreiras (Hartung, 2011). Destaque-se que o delineamento de novos estudos, que enfatizem as emoções relacionadas ao Life Design, faz-se necessário, podendo contribuir com o avanço do novo paradigma.

Informações gerais e específicas relativas ao Life Design, sugestões de leituras aos que desejarem aprofundar o conhecimento sobre o paradigma, referências bibliográficas relevantes, indicações de alguns instrumentos e intervenções baseadas na proposta, além de exemplos e discussões de casos é o que podem esperar os potenciais leitores mediante a degustação da obra.

Por fim, aos interessados nos princípios do Aconselhamento Life Design, esperase que possam refletir acerca de dois questionamentos indicados pelo Grupo Internacional de Pesquisa Life Design e abordados no segundo capítulo do livro. O primeiro relaciona-se a: "Como auxiliar no enfrentamento do déficit de trabalho decente no mundo e das questões socioambientais enfocando a sustentabilidade?" (Ribeiro, Teixeira, \& Duarte, 2019, p. 64). O segundo refere-se a: "Como oferecer um aconselhamento de carreira que coconstrua a consciência" [...] do outro [...] "na nossa carreira futura e a percepção do preço para a humanidade de nossas conquistas pessoais?" (Ribeiro et al., 2019, p. 64). 
Convidamos os apreciadores da obra a exercitarem a reflexão acerca de quão importante se configuram essas questões para as sociedades atuais e para as gerações futuras. Espera-se que cada leitor possa traduzir tais questionamentos em atitudes que favoreçam a sobrevivência do planeta. Desejamos a todos uma ótima leitura!

\section{REFERÊNCIAS}

Hartung, P. J. (2011). Barrier or benefit? Emotion in life-career design. Journal of Career Assessment, 19(3), 296-305. doi: 10.1177/1069072710395536

Ribeiro, M. A., Teixeira, M. A. P., \& Duarte, M. E. (Eds.). (2019). Life Design: Um paradigma contemporâneo em orientação profissional e de carreira. São Paulo, SP: Vetor.

\section{CONFLITOS DE INTERESSES}

Não há conflitos de interesses.

\section{FINANCIAMENTO}

Apoio financeiro do CNPq.

\section{SOBRE OS AUTORES}

Célio Júnio do Carmo Costa é psicólogo, graduado pela Faculdade Ciências da Vida - FCV. Atua como psicólogo clínico e orientador profissional. Membro Alumni UFMG - Grupo transdisciplinar de estudos sobre carreira e egressos.

E-mail: junio.cdc.cost@hotmail.com

Sérgio Dias Cirino é psicólogo, mestre e doutor em Psicologia pela Universidade de São Paulo. Professor titular no Departamento de Psicologia da Universidade Federal de Minas Gerais. Bolsista de Produtividade (PQ2) do CNPq. Coordenador Alumni UFMG - Grupo transdisciplinar de estudos sobre carreira e egressos.

E-mail: sergiocirino99@yahoo.com 